\title{
Internet Gaming Disorder Treatment: A Case Study Evaluation of Four Different Types of Adolescent Problematic Gamers
}

\author{
Alexandra Torres-Rodríguez ${ }^{1} \cdot$ Mark D. Griffiths $^{2}$ • \\ Xavier Carbonell ${ }^{1}$ - Núria Farriols-Hernando ${ }^{1,3}$. \\ Encarna Torres-Jimenez ${ }^{4}$
}

Published online: 5 December 2017

(C) The Author(s) 2017. This article is an open access publication

\begin{abstract}
Research examining Internet Gaming Disorder (IGD) has grown markedly in recent years. However, research on its psychological treatment is still scarce, especially with respect to efficacy of specific programs. The PIPATIC (Programa Individualizado Psicoterapéutico para la Adicción a las Tecnologías de la Información y la Comunicación) program is a 22-session specialized treatment for adolescents with IGD. The present paper briefly outlines the cases of four treatment-seeking male adolescents aged between 13 and 18 years with different clinical IGD profiles undergoing the treatment. A case study using an A-B-A' withdrawal design was conducted. After completing the PIPATIC program, all participants showed clinical improvement in the amount of time spent using video games and in the symptoms of IGD. Results also demonstrated
\end{abstract}

Alexandra Torres-Rodríguez

Alexandrart@blanquerna.url.edu

Mark D. Griffiths

mark.griffiths@ntu.ac.uk

Xavier Carbonell

xaviercs@blanquerna.url.edu

Núria Farriols-Hernando

nuriafh@blanquerna.url.edu

Encarna Torres-Jimenez

encarna.torres@imspbdn.cat

1 Department of Psychology, Universitat Ramon Llull, 34 Císter, 08022 Barcelona, Spain

2 Psychology Department, Nottingham Trent University, 50 Shakespeare Street, Nottingham NG1 4FQ, UK

3 Department of Psychiatry, Hospital of Mataró, Barcelona, Spain

4 Child-Adolescent Mental Health Center (CSMIJ Joan Obiols), 25 De Laietània, 08911 Badalona, Spain 
they received lower scores on clinical tests related to comorbid disorders. In an area with so few studies relating to IGD treatment, the present study is of existential value and contributes clinical information concerning the treatment of IGD in treatment-seeking adolescent patients.

Keywords Internet Gaming Disorder - Video games · Adolescence · Treatment - Case study Cognitive behavioral therapy $\cdot$ Addiction

\section{Background}

Although the study of Internet Gaming Disorder (IGD) has grown markedly in recent years (Griffiths et al. 2016a), peer-reviewed studies evaluating psychological treatments are still scarce. The diagnosis of IGD is not easy, particularly because it is a new disorder only recently included in Section III of the most recent (fifth) edition of Diagnostic and Statistical Manual of Mental Disorders (DSM-5) (American Psychiatric Association 2013). The diagnostic criteria proposed by the APA (2013) appear to have adequate validity and diagnostic precision (Ko et al. 2014). However, there is still no consensus on some issues related to IGD diagnostic criteria (Griffiths et al. 2016b; Király et al. 2015). In addition, its psychological, social, and health consequences require further study (Király et al. 2015; Kuss et al. 2017). Much research has been carried out to define this disorder, clarify its most controversial aspects, and expand the evaluation of specialized treatments (Griffiths et al. 2016a).

Previous studies have shown that cognitive behavior therapy (CBT) can be effective for the psychological treatment of addiction to online video games (Kaptsis et al. 2016; King et al. 2010; Young 2013). Other types of treatment-mostly comprising case studies and small numbers of participants - have claimed treatment efficacy including pharmacotherapy (methylphenidate and bupropion), counseling, and online software based on motivational interviewing (King et al. 2011). Unfortunately, little research has evaluated the effectiveness of IGD treatments, and most therapeutic recommendations tend to be based on those for substance abuse treatment (King et al. 2017). Case reports using data from clinical histories and interviews are also scarce but are important given the lack of literature concerning the treatment of technological addictions, particularly among adolescents (Griffiths 2015). The case study reports in the contemporary literature (Griffiths 2010; King et al. 2012; Schwartz 2013; Torres-Rodríguez and Carbonell 2015) are relevant and important for their qualitative and clinical value. However, they are not as robust as unique case studies with experimental and semi-experimental methodologies, such as withdrawal designs (Tate et al. 2016).

Consequently, there is both an empirical and clinical need to evaluate specialized treatments among adolescents with IGD. The adolescent population uses online video games regularly and presents multiple psychological vulnerabilities intrinsic to this life stage (Kuss et al. 2013; López-Fernandez et al. 2014; Wan and Chiou 2006). For instance, identity has yet to be fully consolidated, and there is a strong feeling of social belonging that could lead to maladaptive behaviors or lack of awareness about the consequences of acts. These are just a few examples regarding the risk factors in developing addictive behaviors and/or other psychological disorders (Kuss and Griffiths 2012a, b; Masten and Garmezy 1985; Steinhausen and Metzke 2001; Wood et al. 2004). To explore overarching issues in the psychological treatment of IGD, the present study evaluates the effects of a specialized treatment in adolescent patients with IGD. To alleviate problems of external validity, a direct inter-participant replication was carried out for four patients with very different clinical characteristics and profile. 


\section{Intervention: PIPATIC Program}

The goal of the newly developed PIPATIC program (Programa Individualizado Psicoterapéutico para la Adicción a las Tecnologías de la información y la comunicación; Torres-Rodriguez et al. 2017) is to offer specialized psychotherapy specifically for adolescents with symptoms of IGD and comorbid disorders. Following previous studies (e.g., Hansen and Lambert 2003; Kadera et al. 1996), and to ensure therapeutic changes in patients, the PIPATIC program is 6 months in duration comprising twenty-two 45-min weekly sessions. The PIPATIC intervention is an individual (person-to-person) therapy carried out by a qualified clinical psychologist. The intervention takes a cognitive behavioral approach and employs standardized psychological guidelines to design a specific psychotherapy program (e.g., Carroll and Nuro 2002; Moscosoa et al. 2013; Schulz et al. 2010). It employs cutting-edge techniques and resources common in psychotherapy (Hofmann and Barlow 2014) including empathy, active and reflexive listening, acceptance, trust, intermediate degrees of directivity, paraphrasing, clarification, synthesis, confrontation, interpretation, feedback, promoting abilities, promoting responsibility, encouraging feelings of self-efficacy, raising insight, and promoting a therapeutic alliance. The program has been described in detail elsewhere (Torres-Rodriguez et al. 2017) but in brief comprises six modules, each consisting of more specific sub-objectives. These are the following:

- Psychoeducational module: individual and family psychoeducation, motivational interviewing, choosing goals and objectives (three sessions);

- Standard IGD intervention module: stimulus control, learning appropriate coping responses, cognitive restructuring, problem solving related to addiction, and exposure (five sessions);

- Intrapersonal module: psychotherapeutic work on identity, self-esteem, self-control, emotional-intelligence, and anxiety control (five sessions);

- Interpersonal module: encouraging adaptive communication skills, assertiveness and increasing communication skills (two sessions);

- Family module: family communication, limits, and affect (three sessions);

- Development of a new lifestyle module: self-observation of improvement, alternative activities, and relapse prevention (two sessions).

Additionally, the PIPATIC program includes two floating sessions that can be incorporated into the module that the therapist chooses, according to the needs of the patient undergoing treatment.

\section{Method}

\section{Participants}

Four male adolescents diagnosed with IGD at two public mental health centers in the Barcelona metropolitan area participated in the study. The patients were voluntary treatmentseekers and diagnosed by clinical psychologists. The inclusion criteria were as follows: (i) endorsing at least five or more of the nine IGD criteria according to DSM-5 (APA 2013), (ii) scoring 71 or more on IGD-20 Test (Pontes et al. 2014) adapted to Spanish population (Fuster 
et al. 2016), (iii) being aged 12 to 18 years, (iv) providing informed consent and consequent participation in the study, (iv) not having a severe mental disorder or intellectual disability, and (v) understanding the national language. The sample chosen to write about in the present paper was specifically selected to represent different clinical characteristics and profiles. Table 1 summarizes the key characteristics of the four participants $(\mathrm{C} 1=$ case study $1, \mathrm{C} 2=$ case study 2 , etc.).

\section{Case 1}

When Case $1(\mathrm{C} 1)$ began treatment, he was 18 years old and was neither in school nor working. From age 14 to 17 years, he suffered bullying, which led him to drop out of school. He lived at home, felt isolated, and developed symptoms of major depression and social phobia (i.e., the inability to interact with people other than his family, fear of going out alone, anhedonia, extreme tiredness, and low self-esteem). These symptoms went unnoticed by his family, and his family was characterized as disorganized and conflict-minimizing with little authoritarianism. During the first months of his self-imposed isolation, $\mathrm{C} 1$ spent $12 \mathrm{~h}$ a day playing Legend Online, League of Legends, Aion, and Call of Duty and exhibited typical symptoms of addiction. He became irritable when he could not play (such as being prevented from playing by a family member or when the Internet connection was lost). He had given up all his hobbies, such as

Table 1 Descriptive overview of the four cases at baseline (pre-treatment)

\begin{tabular}{|c|c|c|c|c|}
\hline & $\mathrm{C} 1$ & $\mathrm{C} 2$ & $\mathrm{C} 3$ & $\mathrm{C} 4$ \\
\hline Age & 18 & 13 & 16 & 17 \\
\hline Occupation & Nothing & Student & Student & Student \\
\hline $\begin{array}{l}\text { Person taking } \\
\text { initiative for } \\
\text { treatment }\end{array}$ & Himself & Mother & Both parents & Himself \\
\hline $\begin{array}{l}\text { Main video game(s) } \\
\text { involved }\end{array}$ & $\begin{array}{l}\text { League of Legends, } \\
\text { Aion, and Call of } \\
\text { Duty }\end{array}$ & $\begin{array}{l}\text { Minecraft, League of } \\
\text { Legends, Pokémon } \\
\text { Online, and Grand } \\
\text { Theft Auto V }\end{array}$ & $\begin{array}{l}\text { World of Warcraft, } \\
\text { League of Legends, } \\
\text { and Call of Duty }\end{array}$ & $\begin{array}{l}\text { League of } \\
\quad \text { Legends }\end{array}$ \\
\hline $\begin{array}{l}\text { Daily hours spent in } \\
\text { video games }\end{array}$ & 10.3 & 5.3 & 5 & 8.3 \\
\hline CERV scores & 45 & 52 & 58 & 52 \\
\hline IGD-20 scores & 79 & 83 & 89 & 79 \\
\hline Comorbid disorders & $\begin{array}{l}\text { Depression and social } \\
\text { phobia }\end{array}$ & $\begin{array}{l}\text { Autism spectrum } \\
\text { disorder (ASD) }\end{array}$ & $\begin{array}{l}\text { Attention deficit } \\
\text { hyperactivity } \\
\text { disorder (ADHD) } \\
\text { and depression }\end{array}$ & None \\
\hline $\begin{array}{l}\text { Relevant MACI } \\
\text { scores }\end{array}$ & $\begin{array}{l}\text { Depressive Affect } \\
\text { (FF): } 108 \\
\text { Introversive (1): } 107\end{array}$ & $\begin{array}{l}\text { Peer Insecurity (E): } \\
111 \\
\text { Anxious Feelings } \\
\text { (EE): } 76\end{array}$ & $\begin{array}{l}\text { Borderline Tendency } \\
\text { (9): } 77 \\
\text { Unruly (6A): } 71\end{array}$ & $\begin{array}{l}\text { (FF): } 66 \\
\text { (1) } 104\end{array}$ \\
\hline Family conflict & 67 & 60 & 67 & 49 \\
\hline School problems & - & $30-\mathrm{C}$ & $33-\mathrm{B}$ & 46 \\
\hline $\begin{array}{l}\text { Social problems } \\
\text { (SP-IV) } \\
\quad(Y S R / 11-18)\end{array}$ & $70-\mathrm{C}$ & $66-\mathrm{B}$ & $66-\mathrm{B}$ & 54 \\
\hline
\end{tabular}

CERV Video Game-Related Experiences Questionnaire; IGD-20 20-item Internet Gaming Disorder Test; $M A C I$ Millon Adolescent Clinical Inventory; Family Conflict is sub-scale of Family Environment Scale (FES); School Problems is a sub-scale of Child Behavior Checklist for ages 6-18 years (CBCL/6-18) 
writing amateur stories and reading novels. At the height of his gaming, he ceased to interact with his few remaining friends, preferring instead to interact with people online.

\section{Case 2}

Case 2 (C2) was 13 years old and had been diagnosed with Asperger syndrome. C2's mother sought therapy for him at the child and adolescent health center. She claimed her son was addicted to online video games including Minecraft in online multiplayer mode, League of Legends, Pokémon Online, Grand Theft Auto V, and Smite. Compared to the other cases described here, C2 displayed most IGD symptoms, along with other clinical traits including insecurity, frequent crying, low self-esteem, difficulty interacting with his peers, stereotypical behaviors (e.g., jumping around in his room as if he were inside a video game), a knife phobia, and generalized immaturity (e.g., enuresis, lack of autonomy, emotional and social immaturity).

\section{Case 3}

At the start of treatment, Case 3 (C3) was 16 years old and was in the fourth year of secondary school. At the age of 8 years, he was diagnosed with attention deficit hyperactivity disorder (ADHD) with oppositional and defiant behaviors. C3 suffered several periods of trauma during his childhood. Firstly, because of his hyperactivity, he became isolated at school and excluded by his peers. Secondly, his parents had several businesses that financially collapsed and they lost their family home due to the debt incurred. Finally, at the age of 15 years, an uncle with whom he had had a very good relationship died of cancer. Following the death of his uncle, $\mathrm{C} 3$ took refuge in video game playing, spending $8 \mathrm{~h}$ per day on World of Warcraft, League of Legends, and Call of Duty. Meanwhile, conflicts at home increased because of his video game playing, and his school performance worsened. C3 became very irritable when his game playing was interrupted by his parents. He insulted his family members, shouted at them, and even deliberately broke household items. Over the period of a year, his isolation increased, he stopped going out with friends, and he stopped playing sports. When C3 asked for help, he was aware of his problems. He spoke of having lost control of his video game playing and his temper.

\section{Case 4}

When Case 4 (C4) began treatment, he was 17 years old and he was studying bachillerato (i.e., college-preparatory studies). He requested help when he realized that he was spending far too much time playing online video games and it was significantly interfering with his academic performance. $\mathrm{C} 4$ explained that he had started playing video games out of boredom and because his friends played video games. Once he had begun to play League of Legends, he felt the need to spend more and more time playing. For an entire year, he played compulsively, resulting in negative consequences including major family conflicts, poor academic performance (he failed six subjects at the end of the school year), social isolation, craving to play video games, psychological dependence, and a total inability to control his behavior. He had no prior history of psychological problems or trauma, but as a result of his addictive video game playing, he began to develop symptoms of depression and guilt. He is the only one of the four cases here without any comorbid disorders prior to IGD. In this sense, he can be considered a "pure" video game addict. 


\section{Measures}

The participants carried out repeated measurements during phases A (baseline or pre-treatment period), B (22-week intervention period), and A' (post-treatment period without intervention). phase A acted as a control and was compared to B and A' (Tate et al. 2016). Moreover, seven key time points were chosen to collect repeated main measures, and self-report diaries were completed in which participants recorded the number of hours spent on online video games. The diagnostic battery comprised an IGD evaluation along with an assessment of comorbid symptoms.

- To assess IGD symptoms, two scales were used, the 17-item Video Game-Related Experiences Questionnaire (CERV; Chamarro et al. 2014) ( $\geq 39$ cut-off point; minimum and maximum scores are 17 and 68), and the 20-item Internet Gaming Disorder Test (IGD20 Test; Pontes et al. 2014) ( $\geq 71$ cut-off point; minimum and maximum scores are 20 and 100) adapted to Spanish population (Fuster et al. 2016).

- The 90-item Symptom Checklist-90-R (SCL-90-R; Derogatis 1996) using a 5-point scale $(0=$ "no problem" to $4=$ "very serious"; minimum and maximum scores are 0 and 360$)$.

The Global Severity Index (GSI) where GSI $=\frac{\text { total values assigned to each item }}{90 \text { items }}$ was used as a quantitative indicator concerning respondent's psychological distress status (minimum and maximum scores are 0-4).

- The 113-item Youth Self-Report for ages 11-18 years (YSR/11-18) (Achenbach and Rescorla 2001) was used to assess behavioral and emotional functioning. The Total Problem Scale (YRS-Total) was used to assess the global score of the behavioral and emotional functioning via the 113 items. The maximum and minimum direct scores are 0 and 226, maximum and minimum $t$-scores are 50 to 100 (60 to 65 is considered as a borderline score, the cut-off point is $\leq 65$ and indicates a score of clinical significance).

- To evaluate personality patterns, expressed concerns and clinical syndromes, the 160-item Millon Adolescent Clinical Inventory (MACI; Millon 1994) was used to take into account $t$-scores over 60 . The minimum and maximum MACI $t$-scores are 0 and 115 . The interpretative clinical benchmarks are the following: 60 to 74 refer to possible presence of traits at the domain level, 75 to 85 likely psychopathology is present, and $\leq 85$ presence of persistence of a specific personality trait or clinical syndrome.

- To evaluate family conflict, the 9-item Family Conflict (FC) sub-scale of the Family Environment Scale (FES; Moos and Moos 1994) was used to assess the level of family unrest from participant's perspective. Minimum and maximum direct scores are 0 and 9 for the ten sub-scales. Minimum and maximum $t$-scores are 0 to 100 , with $\leq 50$ being the cutoff point for severe family conflict.

- To assess social problems, the 11-item Social Problem Scale (IV) of the YSR/11-18 was used (Achenbach and Rescorla 2001). Minimum and maximum direct scores are 0 and 22, minimum and maximum $t$-scores are 50 and 100 (with 65 to 70 borderline scores, and scores $\leq 75$ indicating clinical significance).

- To evaluate the school situation, the 4-item School Scale of the Child Behavior Checklist (CBCL/6-18; Achenbach and Rescorla 2001) was used. Minimum and maximum direct scores are 0 and 6, minimum and maximum $t$-scores are 20 and 65 (with 30 to 35 being borderline scores, and scores $\leq 35$ being of clinical significance).

- To evaluate the alliance and the level of therapeutic change, the 17-item Working Alliance Theory of Change Inventory (WATOCI) was used (Horvath and Greenberg 1986) adapted 
for the Spanish population (Corbella and Botella 2004). The minimum and maximum scores are 17 and 119 .

\section{Procedure and Analysis}

The present study employed an A-B-A' withdrawal design (Byiers et al. 2012; Tate et al. 2016). Phase changes were marked using the following criteria: (i) A-B occurred when all measurements for phase A had been obtained; (ii) B-A' occurred when the intervention was complete; and (iii) phase A' occurred with data collection three months after treatment ended. A visual analysis was used to identify changes within phases and to identify trends regarding the hours spent playing video games (Alresheed et al. 2013). Additionally, an evaluation of the effects and changes in clinical outcomes during the process was carried out comparing the scores extracted during a number of different time points: pre-treatment $\left(t^{1}\right)$, mid-treatment $\left(t^{4}\right)$, post-treatment $\left(t^{6}\right)$, and follow-up 3 months $\left(t^{7}\right)$. A visual analysis table was used to identify the changes between time points and to evaluate if the scores were in the "clinical" range based on each scale's validated cut-offs.

\section{Ethics}

The study was approved by the ethics committees of the mental health centers that participated in the studies and the research team's university ethics committee. The participants and their legal guardians signed consent forms. In presenting the cases, information that could have been used to identify the patients was anonymized. The study procedures were carried out in accordance with the Declaration of Helsinki.

\section{Results}

The clinical characteristics at the start of treatment indicated that all four participants had clinical problems concerning online gaming based on the scores of the IGD-20 Test $(\geq 71)$ and CERV ( $\geq 39$ ), and on some scales of the MACI ( $\geq 60$ points). Participants $C 1, C 2$, and C3 had conflicts in their family (CT-FES $\geq 50$ ). On the Social Problem scale (YSR), C1 had a clinical score $(\geq 70)$ and $C 2$ and $C 3$ had borderline scores concerning clinical significance $(\geq 65)$. On the school scale, $\mathrm{C} 2$ had a clinical score $(<30)$, and $\mathrm{C} 3$ a borderline score concerning clinical significance (30-35). This scale was not administered to $\mathrm{C} 1$ because he was no longer at school.

Figure 1 visually shows the time spent playing online video games throughout the course of the treatment, utilizing data collected via self-report diaries. Figure 1 demonstrates stable intraphase patterns for time spent playing online video games in phases A, B, and A'. The figure also shows an abrupt decrease in playing online video games between phases $\mathrm{A}$ and $\mathrm{B}$. The decrease is seen in all four cases immediately during the first weeks of treatment. The mean $(\bar{X})$ of hours of online gaming per week for phase A was high (49.12 h per week). There was a reduction in the average number of hours spent per week in playing online video games from times $t^{1.4}$ to $t^{6}\left(\overline{\mathrm{X}}_{\text {before }}=50.75 \mathrm{~h}\right.$ per week; $\overline{\mathrm{X}}_{\mathrm{after}}=9 \mathrm{~h}$ per week). Also during phase A, there were differences in daily online gaming on weekdays $\left(\overline{\mathrm{X}}_{\mathrm{week}}=6.68 \mathrm{~h}\right.$ per day; MondayFriday) compared to weekend days $\left(\overline{\mathrm{X}}_{\text {weekend }}=9.08 \mathrm{~h}\right.$; Saturday-Sunday $)$. 


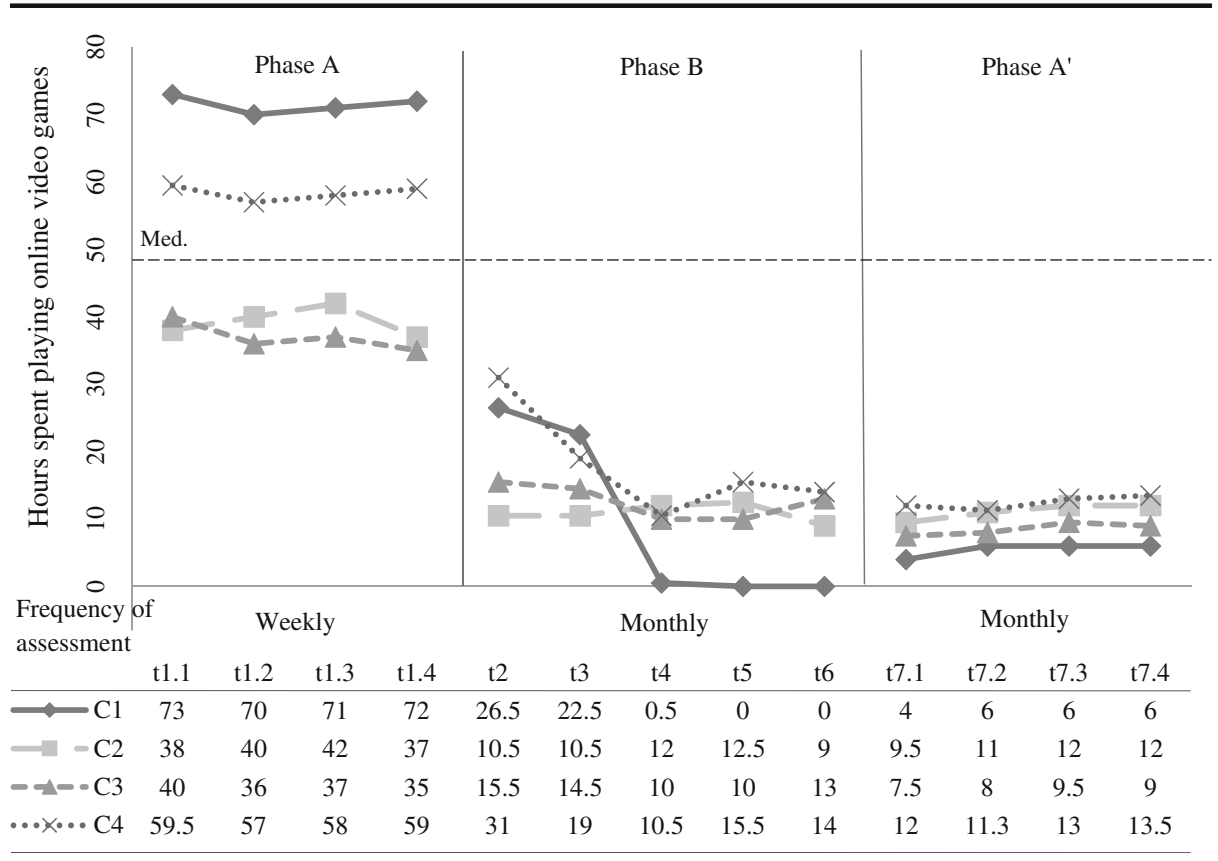

Fig. 1 Visual analysis of hours spent playing video games throughout phases A, B, and A' in the four cases

The pre-post comparison of the scores on the battery of scales showed a reduction tendency (see Table 2). Clinical scores on the IGD-20 Test and the CERV normalized from $t^{1}$ to $t^{6}$, and they remained stable three months after treatment ended (Table $2, t^{6}$ to $t^{7}$ ). General symptoms as assessed by the YSR-Total and SCL-R-PSDI scales notably improved. Scores related to school (CBCL), social problems (YSR), and family conflict (FES) also improved following treatment (Table 2). To evaluate the effects of treatment on specific comorbid diagnoses, the scales of the MACI test were compared. Scores on these scales also decreased: C1: Depressive Affect

Table 2 Comparison between times of scale scores for video game addiction and comorbid symptoms

\begin{tabular}{|c|c|c|c|c|c|c|c|c|c|c|c|c|c|c|c|c|}
\hline \multirow[b]{2}{*}{ Times } & \multicolumn{4}{|l|}{$\mathrm{C} 1$} & \multicolumn{4}{|l|}{$\mathrm{C} 2$} & \multicolumn{4}{|l|}{$\mathrm{C} 3$} & \multicolumn{4}{|l|}{$\mathrm{C} 4$} \\
\hline & $t^{1}$ & $t^{4}$ & $t^{6}$ & $t^{7}$ & $t^{1}$ & $t^{4}$ & $t^{6}$ & $t^{7}$ & $t^{1}$ & $t^{4}$ & $t^{6}$ & $t^{7}$ & $t^{1}$ & $t^{4}$ & $t^{6}$ & $t^{7}$ \\
\hline CERV & 45 & 25 & 18 & 18 & 52 & 22 & 21 & 20 & 58 & 36 & 24 & 23 & 52 & 36 & 26 & 26 \\
\hline IGD & 79 & 37 & 20 & 20 & 83 & 26 & 24 & 26 & 89 & 75 & 32 & 33 & 79 & 64 & 34 & 30 \\
\hline SCL-90-R (GSI) & 2.1 & 1.1 & 0.2 & 0.1 & 1.5 & 0.5 & 0.2 & 0.3 & 0.5 & 0.4 & 0.3 & 0.1 & 0.6 & 0.6 & 0 & 0 \\
\hline YSR-Total & 64 & - & 39 & 33 & $61 \mathrm{~B}$ & - & 45 & 38 & $61 \mathrm{~B}$ & - & 47 & 56 & 56 & - & 35 & 35 \\
\hline FC (FES) & 67 & - & 58 & 54 & 60 & - & 58 & 40 & 67 & - & 54 & 54 & 49 & - & 54 & 49 \\
\hline SP-IV (YSR) & 70 & - & 51 & 50 & 66 & - & 48 & 51 & 66 & - & 51 & 51 & 54 & - & 50 & 50 \\
\hline School (CBCL) & $*$ & - & $*$ & $*$ & 30 & - & 39 & 43 & 33 & - & 37 & 43 & 46 & - & 54 & 54 \\
\hline Alliance (WATOCI) & - & - & 89 & - & - & - & 116 & - & - & - & 112 & - & - & - & 118 & - \\
\hline
\end{tabular}

“-” means a non-application of the instrument in the correspondent temporal moments; “*” means missed data $C E R V$ Video Game-Related Experiences Questionnaire, IGD-20 20-item Internet Gaming Disorder Test, $S C L$ 90-R Symptom Checklist-90-R, GSI global severity index, YRS/11-18 Youth Self-Report for ages 11-18, YSRTotal Total Problem Scale of YSR, SP-IV Social Problem sub-scale of YSR, FES Family Environment Scale, FC Family Conflict sub-scale of FES, $C B C L / 6-18$ Child Behavior Checklist for ages 6-18, School School sub-scale of CBCL, WATOCI Working Alliance Theory of Change Inventory 
$(\mathrm{FF})_{\text {pre }}=108, \mathrm{FF}_{\text {post }}=55$, Introversion $(1)_{\text {pre }}=107,1_{\text {post }}=70 ; \mathrm{C} 2:$ Peer Insecurity $(\mathrm{E})_{\text {pre }}=111$, $\mathrm{E}_{\text {post }}=53$, Anxious Feelings $(\mathrm{EE})_{\text {pre }}=76, \mathrm{EE}_{\text {post }}=92 ; \mathrm{C} 3$ : Borderline Tendency $(9)_{\text {pre }}=77$, $9_{\text {post }}=46$, Unruly $(6 \mathrm{~A})_{\text {pre }}=71,6 \mathrm{~A}_{\text {post }}=71 ; \mathrm{C} 4: \mathrm{FF}_{\text {pre }}=66, \mathrm{FF}_{\text {post }}=29,1_{\text {pre }}=104,1_{\text {post }}=45$. The only exceptions were the EE scale [Anxious Feelings] (for C2) and Scale 9 [Borderline tendency] (for C3), where no decreases occurred. To evaluate the therapeutic alliance and the patients' degree of satisfaction, the WATOCI instrument was used (Corbella and Botella 2004) (Table 2). Positive scores highlight the four participants' satisfaction with the treatment.

\section{Discussion}

The main objective of the present study was to evaluate the effects of the PIPATIC treatment on four adolescent participants with IGD, all who had very different characteristics and profiles. Initially, each of the four adolescents played online video games for $40 \mathrm{~h}$ or more per week and had clinically relevant scores for addiction to video games on the CERV scale and the IGD-20 Test. These results are consistent with those of other studies (e.g., Pontes et al. 2014), which also describe pathological players spending excessive amounts of time gaming (over $40 \mathrm{~h}$ per week).

The immediate and notably inter-phase changes (A-B) are strong evidence of a functional relationship between the treatment and the studied behavior (Kratochwill et al. 2012). In A-BA' withdrawal studies, the problem behavior often increases after treatment is withdrawn, thus demonstrating the decisive role that the treatment has in the individual's control of the behavior (Stake 2006). In the case of psychotherapy, lasting effects are a positive outcome, given that they represent a positive impact on the mental health and long-term autonomy of patients (Stake 2006).

The symptoms of IGD assessed using the IGD-20 Test and the CERV also markedly changed for the better. Given that both instruments assess similar constructs, similar changes were expected in reduced scores over time, and that is what was found. Scores indicating clinical impairments due to online gaming were obtained during phase A and normal scores were obtained by the end of treatment and remained stable at three months post-treatment. Comorbid pathology was reduced by the end of the treatment period and remained at normal levels during the subsequent three months. The relationship between IGD and other comorbid problems has been confirmed in previous studies associating IGD with depression, anxiety, ASD, ADHD, and conduct disorders among others (e.g., Brunborg et al. 2014; King and Delfabbro 2016; Müller et al. 2015; van Rooij et al. 2014). The findings of the present study are strengthened by the fact that scores remained stable at three months post-treatment. These results are consistent with the results of a pilot study in which the same treatment was performed on an adult patient with IGD (Torres-Rodriguez and Carbonell 2015).

Given that all four cases had a completely different etiology leading to their problematic video game playing, one of the most interesting observations is that the PIPATIC treatment was able to significantly reduce the negative symptoms and effects of IGD irrespective of the patients' pathway and predispositions. Three of the patients had pre-existing comorbid disorders (i.e., autistic spectrum disorder, attention deficit hyperactivity disorder with depression, social phobia with depression) whereas the remaining one had no pre-existing disorders at all (with the only pre-condition or motivation for playing appearing to be a low boredom threshold coupled with wanting to fit in with his peers). This demonstrates that even just among four individuals, there are not necessarily common predisposing risk factors in the 
etiology of IGD and that IGD has to be viewed within a biopsychosocial model just like other addictive behaviors (Griffiths 2005). While the sample was self-selecting in that they were all treatment-seeking individuals, the fact that they were all male concurs with previous studies showing that female IGD appears to be rare (e.g., Kuss and Griffiths 2012a, b) and that those in treatment for IGD are also predominantly single males (e.g., Beranuy et al. 2012).

The present study has some limitations common to single-case studies carried out in a clinical setting. First, an intentional sample was used. Second, the use of self-reporting in data collection (in this case self-report diaries) can generate responses subject to well-known biases (such as social desirability and memory recall). Third, in withdrawal studies, treatment is typically ceased as soon as an improvement is observed. The present authors did not follow this protocol and instead carried out the full treatment on all four participants. To withdraw treatment would have been unethical, because it could have harmed the therapeutic relationship and caused adverse effects for the mental health of these vulnerable participants (Moscosoa et al. 2013).

The research presented here contributes to the literature by reporting on the specific effects of a specialized intervention (i.e., the PIPATIC program) in four adolescent patients with IGD. As in any clinical case studies, the findings should be interpreted with caution due to the limited number of cases evaluated. Nonetheless, various authors report the validity of an intervention when similar effects are produced in different replications (Kratochwill et al. 2012). Given these criteria, the findings are encouraging from both empirical and clinical points of view.

\section{Compliance with Ethical Standards}

Conflict of Interest The authors declare that they have no conflict of interest. No funding was received for this study.

Ethical Approval All procedures performed in this study involving human participants were in accordance with the ethical standards of University's Research Ethics Board and with the 1975 Helsinki Declaration.

Informed Consent Informed consent was obtained from all participants.

Open Access This article is distributed under the terms of the Creative Commons Attribution 4.0 International License (http://creativecommons.org/licenses/by/4.0/), which permits unrestricted use, distribution, and reproduction in any medium, provided you give appropriate credit to the original author(s) and the source, provide a link to the Creative Commons license, and indicate if changes were made.

\section{References}

Achenbach, T. M., \& Rescorla, L. A. (2001). Manual for the ASEBA school-age forms and profiles. Burlington, T.V: ASEBA.

Alresheed, F., Hott, B. L., \& Bano, C. (2013). Single subject research: A synthesis of analytic methods. Journal of Special Education Apprenticeship, 2(1), 1-18.

American Psychiatric Association. (2013). DSM-5: Diagnostic and statistical manual of mental disorders (5th ed.). Washington, DC: American Psychiatric Association.

Beranuy, M., Carbonell, X., \& Griffiths, M. (2012). A qualitative analysis of online gaming addicts in treatment. International Journal of Mental Health and Addiction, 11(2), 149-161. https://doi.org/10.1007/s11469-0129405-2.

Brunborg, G. S., Mentzoni, R. A., \& Frøyland, L. R. (2014). Is video gaming, or video game addiction, associated with depression, academic achievement, heavy episodic drinking, or conduct problems? Journal of Behavioral Addictions, 3(1), 27-32. https://doi.org/10.1556/JBA.3.2014.002. 
Byiers, B. J., Reichle, J., \& Symons, F. J. (2012). Single-subject experimental design for evidence-based practice. American Journal of Speech-Language Pathology, 21(4), 397-414. https://doi.org/10.1044/1058-0360(2012 /11-0036).

Carroll, K. M., \& Nuro, K. F. (2002). One size cannot fit all: A stage model for psychotherapy manual development. Clinical Psychology: Science and Practice, 9(4), 396-406.

Chamarro, A., Carbonell, X., Manresa, J. M., Munoz-Miralles, R., Ortega-Gonzalez, R., López-Morron, M. R., et al. (2014). The questionnaire of experiences associated with video games (CERV): An instrument to detect the problematic use of video games in Spanish adolescents. Adicciones, 26(26), 303-311.

Corbella, S., \& Botella, L. (2004). Psychometric properties of the Spanish version of the Working Alliance Theory of Change Inventory (WATOCI). Psicothema, 16(4), 702-705.

Derogatis, L. R. (1996). SCL-90-R: Symptom Checklist-90-R: Administration, scoring, and procedures manual. Minneapolis: NCS Pearson.

Fuster, H., Carbonell, X., Pontes, H. M., \& Griffiths, M. D. (2016). Spanish validation of the Internet Gaming Disorder (IGD-20) Test. Computers in Human Behavior, 56, 215-224. https://doi.org/10.1016/j. chb.2015.11.050.

Griffiths, M. (2005). A “components" model of addiction within a biopsychosocial framework. Journal of Substance Use, 10(4), 191-197. https://doi.org/10.1080/14659890500114359.

Griffiths, M. D. (2010). The role of context in online gaming excess and addiction: Some case study evidence. International Journal of Mental Health and Addiction, 8(1), 119-125. https://doi.org/10.1007/s11469-0099229-x.

Griffiths, M. D. (2015). Problematic technology use during adolescence: Why don't teenagers seek treatment? Education and Health, 33(1), 6-9.

Griffiths, M. D., Kuss, D. J., Billieux, J., \& Pontes, H. M. (2016a). The evolution of internet addiction: A global perspective. Addictive Behaviors, 53, 193-195. https://doi.org/10.1016/j.addbeh.2015.11.001.

Griffiths, M. D., van Rooij, A. J., Kardefelt-Winther, D., Starcevic, V., Király, O., Pallesen, S., et al. (2016b). Working towards an international consensus on criteria for assessing internet gaming disorder: A critical commentary on Petry et al. (2014). Addiction, 111(1), 167-175. https://doi.org/10.1111/add.13057.

Hansen, N. B., \& Lambert, M. J. (2003). An evaluation of the dose-response relationship in naturalistic treatment settings using survival analysis. Mental Health Services Research, 5(1), 1-12. https://doi.org/10.1023 /A:1021751307358.

Hofmann, S. G., \& Barlow, D. H. (2014). Evidence-based psychological interventions and the common factors approach: The beginnings of a rapprochement? Psychotherapy, 51(4), 510-513. https://doi.org/10.1037 /a0037045.

Horvath, A. O., \& Greenberg, L. S. (1986). The development of the working alliance inventory. In L. S. Greenberg \& W. M. Pinsoff (Eds.), The psychotherapeutic process: a research handbook (pp. 529-556). New York: Guilford Press.

Kadera, S. W., Lambert, M. J., \& Andrews, A. A. (1996). How much therapy is really enough? A session-bysession analysis of the psychotherapy dose-effect relationship. Journal of Psychotherapy Practice and Research, 5(2), 132-151.

Kaptsis, D., King, D. L., Delfabbro, P. H., \& Gradisar, M. (2016). Withdrawal symptoms in internet gaming disorder: A systematic review. Clinical Psychology Review, 43, 58-66. https://doi.org/10.1016/j. cpr.2015.11.006.

King, D., Delfabbro, P., \& Griffiths, M. (2010). Cognitive behavioral therapy for problematic video game players: Conceptual considerations and practice issues. Journal of Cyber Therapy and Rehabilitation, 3(3), 261-273.

King, D., Delfabbro, P., Griffiths, M., \& Gradisar, M. (2011). Assessing clinical trials of Internet addiction treatment: A systematic review and CONSORT evaluation. Clinical Psychology Review, 31(7), 1110-1116. https://doi.org/10.1016/j.cpr.2011.06.009.

King, D. L., \& Delfabbro, P. H. (2016). Features of parent-child relationships in adolescents with Internet Gaming Disorder. International Journal of Mental Health and Addiction. https://doi.org/10.1007/s11469016-9699-6.

King, D. L., Delfabbro, P. H., Griffiths, M. D., \& Gradisar, M. (2012). Cognitive-behavioral approaches to outpatient treatment of internet addiction in children and adolescents. Journal of Clinical Psychology, 68(11), 1185-1195. https://doi.org/10.1002/jclp.21918.

King, D. L., Delfabbro, P. H., Wu, A. M. S., Doh, Y. Y., Kuss, D. J., Pallesen, S., et al. (2017). Treatment of Internet gaming disorder: An international systematic review and CONSORT evaluation. Clinical Psychology Review, 54(November 2016, 123-133. https://doi.org/10.1016/j.cpr.2017.04.002.

Király, O., Griffiths, M. D., \& Demetrovics, Z. (2015). Internet Gaming Disorder and the DSM-5: Conceptualization, debates, and controversies. Current Addiction Reports, 2(3), 254-262. https://oi. org/10.1007/s40429-015-0066-7. 
Ko, C.-H., Yen, J.-Y., Chen, S.-H., Wang, P.-W., Chen, C.-S., \& Yen, C.-F. (2014). Evaluation of the diagnostic criteria of Internet gaming disorder in the DSM-5 among young adults in Taiwan. Journal of Psychiatric Research, 53, 103-110. https://doi.org/10.1016/j.jpsychires.2014.02.008.

Kratochwill, T. R., Hitchcock, J. H., Horner, R. H., Levin, J. R., Odom, S. L., Rindskopf, D. M., \& Shadish, W. R. (2012). Single-case intervention research design standards. Remedial and Special Education, 34(1), 2638. https://doi.org/10.1177/0741932512452794.

Kuss, D. J., \& Griffiths, M. D. (2012a). Internet gaming addiction: A systematic review of empirical research. International Journal of Mental Health and Addiction, 10(2), 278-296. https://doi.org/10.1007/s11469-0119318-5.

Kuss, D. J., \& Griffiths, M. D. (2012b). Online gaming addiction in children and adolescents: A review of empirical research. Journal of Behavioral Addictions, 1(1), 3-22. https://doi.org/10.1556/JBA.1.2012.1.1.

Kuss, D. J., Griffiths, M. D., \& Pontes, H. M. (2017). Chaos and confusion in DSM-5 diagnosis of Internet Gaming Disorder: Issues, concerns, and recommendations for clarity in the field. Journal of Behavioral Addictions, 6, 103-109. https://doi.org/10.1556/2006.5.2016.062.

Kuss, D., Van Rooij, A., \& Shorter, G. (2013). Internet addiction in adolescents: Prevalence and risk factors. Computers in Human Behavior, 29(5), 1987-1996. https://doi.org/10.1016/j.chb.2013.04.002.

López-Fernandez, O., Honrubia-Serrano, M. L., Baguley, T., \& Griffiths, M. D. (2014). Pathological video game playing in Spanish and British adolescents: Towards the exploration of Internet Gaming Disorder symptomatology. Computers in Human Behavior, 41, 304-312. https://oi.org/10.1016/j.chb.2014.10.011.

Masten, A. S., \& Garmezy, N. (1985). Risk, vulnerability, and protective factors in developmental psychopathology. In A. S. Masten \& N. Garmezy (Eds.), Advances in clinical child psychology (pp. 1-52). Minnesota: Springer.

Millon, T. (1994). Millon adolescent clinical inventory (MACI). Minneapolis: National Computers Systems.

Moos, R. \& Moos, B. (1994). Family Environment Scale Manual: Development, Applications, Research - Third Edition. Palo Alto, CA: Consulting Psychologist Press.

Moscosoa, S. C., Chaves, S. S., Vidal, M. P., \& Anguera, M. T. (2013). Reporting a program evaluation: Needs, program plan, intervention, and decisions. International Journal of Clinical and Health Psychology, 13(1), 58-66. https://doi.org/10.1016/S1697-2600(13)70008-5.

Müller, K. W., Janikian, M., Dreier, M., Wölfling, K., Beutel, M. E., Tzavara, C., et al. (2015). Regular gaming behavior and internet gaming disorder in European adolescents: Results from a cross-national representative survey of prevalence, predictors, and psychopathological correlates. European Child \& Adolescent Psychiatry, 24, 565-574. https://doi.org/10.1007/s00787-014-0611-2.

Pontes, H. M., Király, O., Demetrovics, Z., \& Griffiths, M. D. (2014). The conceptualisation and measurement of DSM-5 Internet Gaming Disorder: The development of the IGD-20 Test. PLoS ONE, 9(10), e110137. https://doi.org/10.1371/journal.pone.0110137.

Schulz, K. F., Altman, D. G., Moher, D., \& Group, C. (2010). CONSORT 2010 statement: Updated guidelines for reporting parallel group randomized trials. Annals of Internal Medicine, 152(11), 726-732. https://doi. org/10.7326/0003-4819-152-11-201006010-00232.

Schwartz, R. H. (2013). Excessive participation in online internet action games by two American teenagers: Case report, description of extent of overuse, and adverse consequences. Pediatrics, 3, 201-203.

Stake, R. E. (2006). Multiple case study analysis. New York: The Guildford Press.

Steinhausen, H. C., \& Metzke, C. W. (2001). Risk, compensatory, vulnerability, and protective factors influencing mental health in adolescence. Journal of Youth and Adolescence, 30(3), 259-280.

Tate, R. L., Perdices, M., Rosenkoetter, U., Shadish, W., Vohra, S., Barlow, D., et al. (2016). The single-case reporting guideline in behavioural interventions (SCRIBE) 2016: Explanation and elaboration. Archives of Scientific Psychology, 96(7), 1-10.

Torres-Rodríguez, A., \& Carbonell, X. (2015). Adicción a los videojuegos en línea: Tratamiento mediante el programa PIPATIC. Aloma, 33(2), 67-75.

Torres-Rodriguez, A., Griffiths, M. D. \& Carbonell, X. (2017). The treatment of Internet Gaming Disorder: A brief overview of the PIPATIC program. International Journal of Mental Health and Addiction. https://doi. org/10.1007/s11469-017-9825-0.

van Rooij, A. J., Kuss, D. J., Griffiths, M. D., Shorter, G. W., Schoenmakers, M. T., \& Van De Mheen, D. (2014). The (co-)occurrence of problematic video gaming, substance use, and psychosocial problems in adolescents. Journal of Behavioral Addictions, 3(3), 157-165. https://doi.org/10.1556/JBA.3.2014.013.

Wan, C., \& Chiou, W. (2006). Why are adolescents addicted to online gaming? CyberPsychology \& Behavior, 9(6), 762-766. https://doi.org/10.1089/cpb.2006.9.762.

Wood, R., Gupta, R., Derevensky, J., \& Griffiths, M. (2004). Video game playing and gambling in adolescents: Common risk factors. Journal of Child \& Adolescent Substance Abuse, 14(1), 77-100.

Young, K. S. (2013). Treatment outcomes using CBT-IA with Internet-addicted patients. Journal of Behavioral Addictions, 2(4), 209-215. https://doi.org/10.1556/JBA.2.2013.4.3. 